\title{
Teores de Nutrientes do Solo sob Sistema Agroflorestal Manejado com e sem Queima no Estado do Pará
}

\author{
Francinaldo Oliveira Matos ${ }^{1}$, Rosecélia Moreira da Silva Castro ${ }^{2}$, \\ Maria de Lourdes Pinheiro Ruivo ${ }^{2}$, Quêzia Leandro de Moura ${ }^{3}$ \\ ${ }^{1}$ Departamento de Engenharia Ambiental, Universidade do Estado do Pará - UEPA, \\ Museu Paraense Emílio Goeldi - MPEG \\ ${ }^{2}$ Museu Paraense Emílio Goeldi - MPEG \\ ${ }^{3}$ Programa de Pós-Graduação em Ciências Ambientais, Universidade Federal do Pará - UFPA
}

\begin{abstract}
RESUMO
Este trabalho teve como objetivo avaliar o teor de nutrientes em solos sob sistemas agroflorestais manejados com e sem queima da vegetação, em uma propriedade de agricultura familiar na comunidade Benjamim Constant, no município de Bragança-PA. Para o desenvolvimento deste estudo, foram estabelecidas três áreas experimentárias: 1 ) sistema agroflorestal com corte e queima da vegetação; 2 ) sistema agroflorestal sem queima e com raleamento da vegetação, e 3) floresta secundária de 30 anos de idade. Em cada área, foram coletadas amostras de terra nas profundidades $0-5 ; 5-10 ; 10-20 \mathrm{~cm}$. Na ocorrência de diferenças significativas entre os tratamentos, o teste de Tukey foi utilizado para comparar as médias, considerando-se um nível de $5 \%$ de probabilidade. Os maiores valores de $\mathrm{pH}$, fósforo e acidez potencial foram observados no sistema manejado com queima da vegetação, provavelmente por causa de o experimento encontrar-se em anos iniciais e o efeito fertilizador das cinzas ainda se fazer no solo.
\end{abstract}

Palavras-chave: sistemas agroflorestais, nutrientes do solo, agricultura familiar.

\section{Soil Nutrients in Agroforestry with and without Burning in Pará}

\begin{abstract}
This study aimed to evaluate the nutrient content in soils under agroforestry systems managed with no burning and burning of vegetation in a family farm in the community, Benjamin Constant, in the municipality of Bragança-PA. To develop this study were three experimental areas: 1) agroforestry system to cutting and burning of vegetation, 2) agroforestry system without burning and thinning of vegetation and 3) secondary forest 30 years of age. In each area were sampled soil depths $0-5 ; 5-10 ; 10-20 \mathrm{~cm}$. In the event of significant differences between treatments, Tukey's test was used to compare means, considering a 5\% level of probability. The highest values of $\mathrm{pH}$, potential acidity and phosphorus were observed in the system managed with burning of vegetation, probably because the experiment found in the early years and the fertilizing effect of the ash is still present in the soil
\end{abstract}

Keywords: agroforestry, soil nutrients, family farming. 


\section{INTRODUÇÃO}

Os solos amazônicos são altamente intemperizados e caracterizados por acidez elevada, alta saturação por alumínio e baixa concentração de nutrientes, em função das elevadas taxas de lixiviação. As unidades de solos predominantes na região são os Latossolos e Argissolos, com argilas de baixa carga e predomínio de caulinita (Osakada, 2009; Vieira \& Santos, 1987).

A exploração agrícola na Amazônia vem sendo realizada com o uso indiscriminado do fogo, sendo caracterizada pela derrubada e pela queima de florestas primárias e secundárias para limpeza e “adubação" da área. A queima é considerada pelos produtores agrícolas como um método eficaz de preparo da terra antes do plantio de culturas e para a renovação de pastagens, pois, além de eliminar a vegetação invasora, produz cinzas ricas em nutrientes que, em curto prazo, estimula o crescimento de gramíneas forrageiras (Nepstad et al., 1999).

Entretanto, diversos estudos comprovam que a ação do fogo provoca uma série de modificações de naturezas física, química e biológica no solo, como: redução ou alteração da população microbiana; aumento temporário da disponibilidade de nutrientes; alteração no $\mathrm{pH}$; aumento do teor de carbono, e oxidação da matéria orgânica (Santos et al., 1992). A prática da queima também pode alterar os teores de umidade do solo em razão de mudanças nas taxas de infiltração e de evaporação, na porosidade, na repelência do solo à água, como também causar a interrupção da continuidade dos seus processos biológicos, que são responsáveis pela decomposição da matéria orgânica (Neary et al., 1999; Hölscher et al., 1997).

No Estado do Pará, assim como em vários locais do Brasil, o sistema de corte e queima é um procedimento básico da agricultura tradicional; este é, em parte, responsável pela agricultura migratória ainda existente na região e pelo surgimento de extensas áreas de florestas secundárias. O Estado do Pará possui a maior área absoluta de floresta secundária da Amazônia, sendo que as maiores extensões estão na microrregião Bragantina, onde as florestas secundárias ocupam $53 \%$ da região; esta é predominantemente ocupada por pequenos produtores (Gomes, 2007; Ferreira, 2008).

A região Bragantina, localizada no Nordeste Paraense, é caracterizada pelo predomínio de florestas secundárias e pela degradação crescente e descontrolada que vem ocorrendo há mais de um século, gerando a fragmentação das florestas de terra firme. Nesse processo, a vegetação contínua é dividida em fragmentos de tamanho, forma e idades variados, e são ladeados por plantações, pastagens e capoeiras em diferentes níveis de regeneração, gerando verdadeiros mosaicos na paisagem (Vieira et al., 2007).

Uma das alternativas adotadas para aproveitamento das extensas áreas de florestas secundárias de forma viável e sustentável na região Amazônica tem sido a utilização de sistemas agroflorestais (SAFs). A implantação de SAFs vem sendo direcionada para várias regiões, dentre as quais a Amazônica, onde os modelos tradicionais de exploração e desmatamentos seguidos pela atividade agropecuária já exportaram muitos nutrientes. Esses sistemas tornam-se uma importante alternativa para a geração de produtos agrícolas, enquanto proporcionam a recuperação do ambiente, melhorando os atributos do solo e, consequentemente, a vegetação nele existente (Lima et al., 2011).

A utilização dos SAFs tem sido considerada como alternativa de otimização do uso da terra por conciliar a produção florestal com a de alimentos, conservando o solo, diminuindo o impacto causado por práticas agrícolas e favorecendo a ciclagem dos nutrientes por meio do maior aporte de serapilheira (Lima et al., 2007).

$\mathrm{Na}$ região Amazônica, os SAFs representam uma opção estratégica para os pequenos produtores, principalmente pela baixa demanda de insumos, pelo aproveitamento intensivo da mão de obra familiar e pelo maior rendimento líquido por unidade de área em comparação com sistemas convencionais de produção. O SAF predominante na região é o da agricultura itinerante, na qual o preparo do solo é feito com corte e queima da vegetação primária ou secundária para os cultivos anuais e, em seguida, o solo é deixado em pousio para regeneração agrícola 
(5 a 10 anos), enquanto uma nova área é explorada (Gliessman, 2001).

A agricultura itinerante, apesar de ser considerada um sistema agroflorestal (SAF), é uma importante alternativa no uso sustentável do ecossistema do trópico úmido e necessita de adaptação para melhor contribuir com a dinâmica produtiva do sistema, principalmente no que se refere aos ganhos de nutrientes do solo e à manutenção do SAF por um maior período em uma mesma área.

A necessidade do uso de novas práticas agroflorestais - que favoreçam o balanço de nutrientes no cultivo e ampliem a oferta de nutrientes aos cultivos subsequentes sem diminuir a renda do produtor - gerou o desenvolvimento deste trabalho com o objetivo de comparar a concentração de nutrientes de solos em dois sistemas agroflorestais, denominados SAF 1, no qual houve corte e queima da vegetação, e SAF 2, com corte e raleamento da vegetação, para descobrir qual tratamento melhor favorece a produtividade agrícola sustentável.

\section{MATERIAL E MÉTODOS}

\subsection{Meio físico}

O estudo foi desenvolvido no município de Bragança-PA, especificamente na comunidade Benjamim Constant (Figura 1), que fica localizada na microrregião do Nordeste Paraense, distante $210 \mathrm{~km}$ da cidade de Belém-PA. Localizada entre as coordenadas geográficas de $1^{\circ} 00^{\prime} 00^{\prime \prime}$ e $1^{\circ} 10^{\prime} 00^{\prime \prime} \mathrm{S}$, e $46^{\circ} 40^{\prime} 00^{\prime \prime}$ e $46^{\circ} 50^{\prime} 00^{\prime \prime} \mathrm{O}$ de Greenwich, possui área territorial de $2.090 \mathrm{~km}^{2}$, com população de 113.165 habitantes (IBGE, 2010).

O clima de Bragança é classificado como Aw de acordo com Köppen, com temperatura e precipitação média anual de aproximadamente

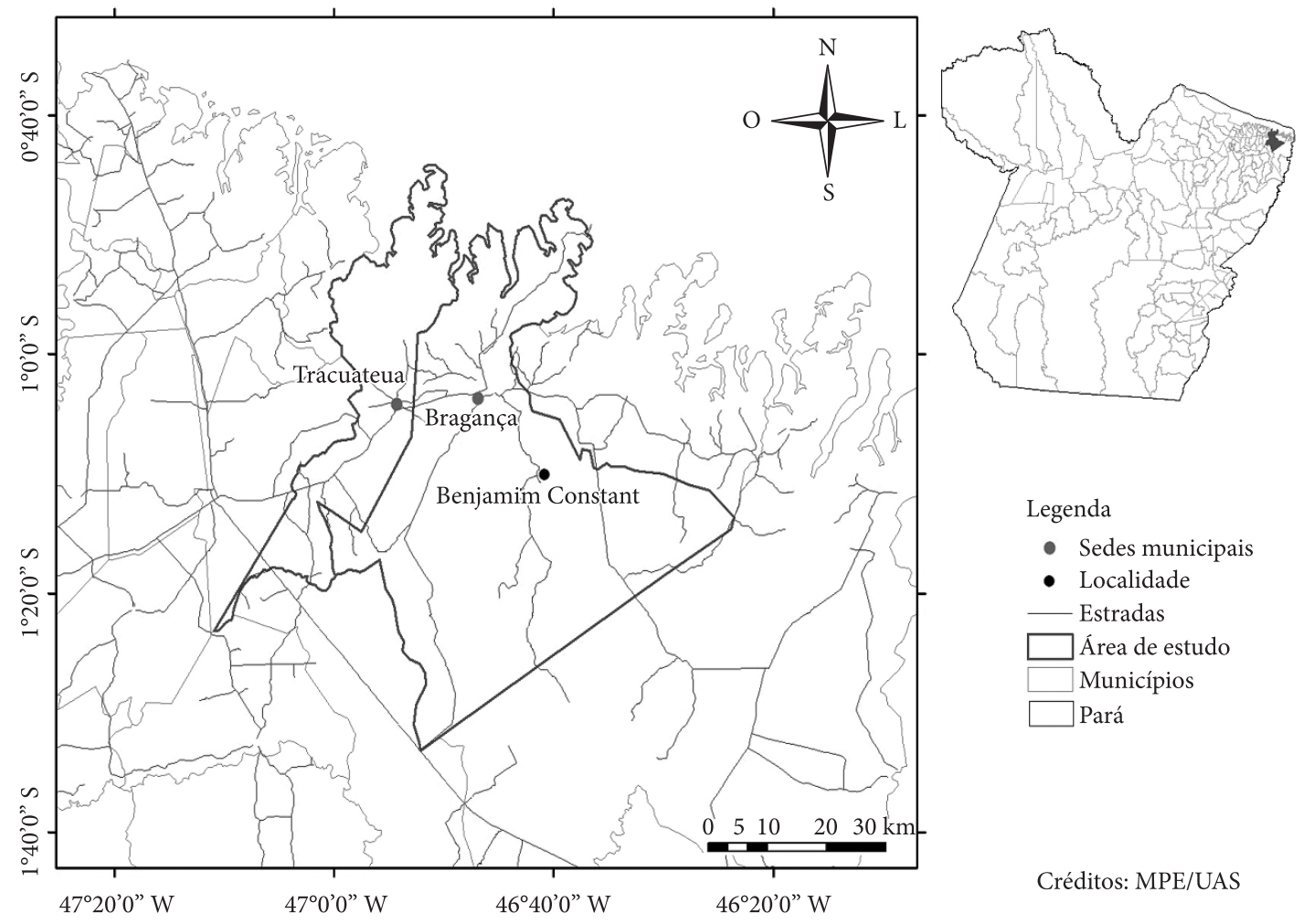

Figura 1. Mapa da localidade de Benjamin Constant, município de Bragança-PA.

Figure 1. Map of the town of Benjamin Constant, the municipality of Bragança-PA. Fonte: UAS, Museu Paraense Emílio Goeldi (2010) apud Castro et al. (2010). 
$25{ }^{\circ} \mathrm{C}$ e $3.000 \mathrm{~mm}$, respectivamente; a umidade relativa do ar está em torno de 80 a $91 \%$ e a insolação, entre 2.200 a 2.400 horas/ano.

Os solos da região Bragantina são ácidos e fortemente ácidos, de boa drenagem por serem permeáveis e de baixa fertilidade natural. A predominância é o Latossolo Amarelo Distrófico (LAD) textura média. A área apresenta solos de terra firme em maior proporção, além de solos de mangue nas proximidades do litoral, formado em condições de hidromorfismo e por sedimentos aluviais (Embrapa, 1999; Rios et al., 2001).

A vegetação é caracterizada como floresta equatorial subperenifólia, apresentando uma fitofisionomia e uma estrutura variada, de porte médio a alto de seus indivíduos, podendo estes atingir até mais de $40 \mathrm{~m}$ de altura. A área experimental está localizada em uma zona de transição entre Amazônia e Brasil Central, com extensas áreas de vegetação secundária, em diferentes idades e distintos graus de sucessão vegetal, culturas agrícolas e áreas de pastagem provenientes de sucessivos ciclos de corte e queima, plantio e pousio (Denich, 1991; Vieira et al., 2007).

\section{2. Área experimental}

Os sistemas agroflorestais foram instalados em 2005 e foram conduzidos em propriedades agrícolas de produtores familiares na comunidade Benjamin Constant, de latitude $1^{\circ} 11^{\prime} 16^{\prime}$ S e longitude $46^{\circ} 40^{\prime} 36^{\prime \prime}$, a $28 \mathrm{~km}$ da sede do município de Bragança. A área é composta por vegetação secundária de aproximadamente 40 anos, tendo sido anteriormente utilizada como agricultura de subsistência no sistema de corte-queima.

A área experimental, constituída de $6804 \mathrm{~m}^{2}$, foi dividida em três sistemas: S1 - área de floresta secundária onde houve corte e queima da vegetação para implantação do SAF; S2 - área de floresta secundária onde houve corte e raleamento da vegetação para posterior implantação do SAF; e S3 - área de capoeira utilizada como testemunho para os resultados obtidos nos tratamentos. Os sistemas das áreas 1 e 2 foram separados entre si por uma faixa de vegetação de capoeira de $10 \mathrm{~m}$ de largura. As características químicas do solo, anteriores aos tratos culturais, estão na Tabela 1 , sendo ambos de baixa fertilidade química.

No sistema 1, o preparo da área foi feito de forma tradicional com corte e queima da vegetação secundária para a implantação de paricá (Schizolobium amazonicum Huber ex Ducke), açaí (Euterpe oleracea Mart) e cupuaçu (Theobroma grandiflorum Schum).

No sistema 2, o preparo de área deu-se no mesmo período, quando foi feito o raleamento da vegetação para a implantação das mesmas culturas. Em seguida, procedeu-se a adubação verde de cobertura Chamaecrista rupens, que foi roçada na época de florescimento, deixando a biomassa vegetal sobre o solo. Nos dois tratamentos, as plantas de paricá e de açaí foram implantadas em espaçamento $3 \times 3 \mathrm{~m}$ e as de cupuaçu, em espaçamento $8 \times 8 \mathrm{~m}$.

\subsection{Coletas e determinação das características químicas}

A coleta das amostras de terra foi realizada no mês de agosto de 2009, seguindo os procedimentos propostos pelo Manual de Descrição e Coleta de Solo no Campo (Lemos \& Santos, 2002). Foram sorteados, aleatoriamente, quatro pontos para abertura de minitrincheiras, em cada área experimental, de onde foram coletadas amostras de terra nas profundidades $0-5,5-10$, e $10-20 \mathrm{~cm}$. As amostras de terra foram acondicionadas em sacos plásticos e enviadas

Tabela 1. Caracterização química do solo da área em estudo antes da implantação dos SAFs.

Table 1. Chemical characterization of the soil of the study area prior to deployment of the SAFs.

\begin{tabular}{|c|c|c|c|c|c|c|c|c|c|}
\hline & \multirow{2}{*}{$\mathrm{pH} \mathrm{H}_{2} \mathrm{O}$} & MO & $\mathbf{N}$ & $\mathbf{K}$ & $\mathbf{P}$ & $\mathrm{H}+\mathrm{AL}$ & AL+ & $\mathrm{Ca}$ & $\mathrm{Mg}$ \\
\hline & & \multicolumn{2}{|c|}{$\left(\mathrm{g} \mathrm{kg}^{-1}\right)$} & \multicolumn{2}{|c|}{$\left(\mathrm{mg} \mathrm{dm}^{-3}\right)$} & \multicolumn{4}{|c|}{$\left(\mathrm{cmol} \mathrm{dm}^{-3}\right)$} \\
\hline SAF1 & 4,74 & 15,02 & 0,85 & 22,88 & 2,57 & 5,28 & 0,85 & 0,78 & 0,68 \\
\hline SAF2 & 4,74 & 15,08 & 0,86 & 22,89 & 2,55 & 5,27 & 0,85 & 0,82 & 0,6 \\
\hline
\end{tabular}

MO (matéria orgânica), N (nitrogênio), K(potássio), P (fósforo), H+AL (acidez potencial), AL+ (Alumínio), Ca (cálcio) e Mg (magnésio). Fonte: Ribeiro, 2009. 
ao Laboratório de Análises Químicas do Museu Paraense Emílio Goeldi (MPEG) para análises químicas $\left(\mathrm{pH} \mathrm{H}_{2} \mathrm{O}\right.$, acidez potencial, carbono orgânico, fósforo, nitrogênio orgânico e potássio trocável), segundo o Manual de Métodos de Análise de Solo (Embrapa, 1997).

\subsection{Tratamento dos dados}

Os dados obtidos foram submetidos à análise de variância (ANOVA) e as médias foram comparadas pelo teste de Tukey em nível de $5 \%$ de probabilidade. Foi efetuado ainda o teste de correlação de Pearson entre os nutrientes em cada sistema. As análises estatísticas foram realizadas pelo programa ASSISTAT (versão 7.6 beta).

\section{RESULTADOS E DISCUSSÃO}

Os diferentes sistemas de manejo florestal apresentaram significância nos atributos químicos do Latossolo estudado, sendo os maiores teores observados na área do sistema 1 , provavelmente pelo efeito das cinzas decorrentes das queimadas então relativamente recentes.

\subsection{Valores de $\mathrm{pH}_{2} \mathrm{O}$, carbono orgânico e acidez potencial}

Os valores médios de $\mathrm{pH}$ não apresentaram diferenças significativas entre os sistemas estudados (Figura 2a), com as mesmas interpretações de níveis de acidez ativa do solo quando do início dos estudos (Tabela 2), em acordo com os quantificados por Ribeiro (2009) em solos da Amazônia. Maiores valores de $\mathrm{pH}$ verificados nos solos sob sistema 1 podem ser justificados pela presença de cátions básicos provenientes da deposição de cinzas na camada superficial do solo, pós-queima da vegetação (Souza, 1995; Silva et al., 2006).

Vale ressaltar que os baixos valores de $\mathrm{pH}$ caracterizam condições desfavoráveis para o pleno desenvolvimento de grande parte de culturas agrícolas (Malavolta, 2006; Novais et al., 2007). Esse fator, em se tratando de espécies nativas da região amazônica - no caso, paricá, açaí e cupuaçu, que são adaptadas a tal ambiência -, provavelmente não interfere no desenvolvimento dessas espécies. Contudo, os valores encontrados mostram-se superiores aos identificados por Melo (2004) em floresta secundária de 40 anos, localizada também no município de Bragança-PA.

Por meio da análise estatística, verificaram-se diferenças significativas $(\mathrm{p}<0,05)$ nas concentrações médias da acidez potencial entre as áreas com queima (S1) e sem queima (S2) da vegetação (Tabela 3), com maior concentração na área de SAF com queima (Figura 2b). Heringer et al. (2002), ao avaliarem as características de um Latossolo Vermelho sob pastagem natural submetido à queima, também encontraram maiores valores de acidez potencial. Contudo, o aumento na acidez potencial observado no $\mathrm{S} 1$ é resultado do efeito fertilizador dos óxidos presentes nas cinzas, que retornam rapidamente aos valores iniciais (Rheinheimer et al., 2003a). (a)

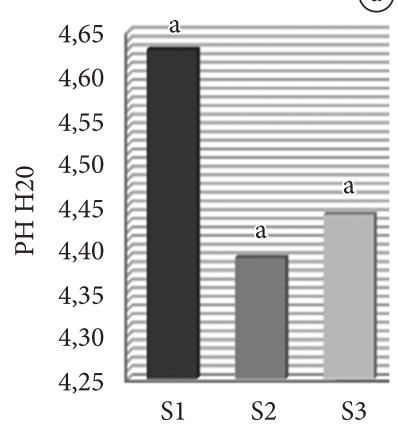

(b)

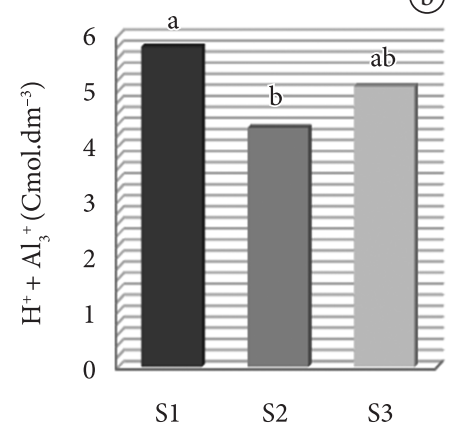

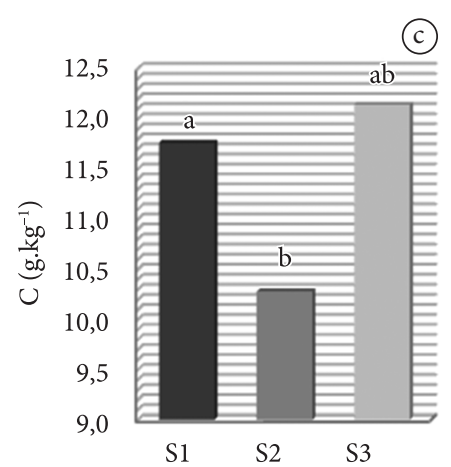

Figura 2. a) pH em água; b) acidez potencial; c) Carbono orgânico. Letras iguais não diferem entre si pelo teste de Tukey a $5 \%$ de probabilidade.

Figure 2. a) $\mathrm{pH}$ in water, b) potential acidity; c) organic carbon. Same letter do not differ by test Tukey $5 \%$ probability level. 
Conforme ilustrado na Figura $2 c$, os maiores teores de carbono orgânico do solo foram verificados na área sob capoeira $\left(12,14 \mathrm{~g} \mathrm{~kg}^{-1}\right)$. Esse valor é superior aos verificados por Melo (2004) e Ribeiro (2009): $8,71 \mathrm{~g} \mathrm{~kg}^{-1}$ e 10,34 $\mathrm{g} \mathrm{kg}^{-1}$, respectivamente, na mesma área de estudo. Comparando-se os sistemas 1 e 2, é possível observar que os maiores valores médios de carbono orgânico foram verificados no sistema 1; porém, só houve diferença significativa entre as áreas S2 e S3 (testemunha).

A decomposição rápida e contínua da $\mathrm{MO}$, como consequência de altos índices de temperatura e umidade típicos da região Amazônica, pode ser apontada como responsável pela alta acidez desses solos, o que se mostra de acordo com os resultados de acidez e $\mathrm{C}$ encontrados entre os sistemas 1 e 3 , em relação ao sistema 2.

\subsection{Fósforo, nitrogênio e potássio trocável}

Quando comparadas aos valores iniciais encontrados sob os diferentes sistemas florestais $\left(2,57 \mathrm{mg} \cdot \mathrm{dm}^{-3}\right)$, as concentrações médias de fósforo (P) aumentaram nos dois SAFs (Figura $3 \mathrm{~b}$ ), sendo maior na área com queima $\left(5,59 \mathrm{mg} \cdot \mathrm{dm}^{-3}\right)$. De acordo com classes de interpretação da disponibilidade para o fósforo trocável, ajustada com teores de argila do solo (Malavolta, 2006), em todos os sistemas avaliados os valores são muito baixos, mesmo sendo sistemas caracterizados pela ausência de revolvimento e em que se prioriza o aporte de resíduos vegetais na superfície do solo.

Embora baixos, os valores de $\mathrm{P}$ foram superiores no sistema com derruba e queima da vegetação, processo provavelmente vinculado com o aumento das disponibilidades desse elemento. Esse fator estaria relacionando à elevação do $\mathrm{pH}$ decorrente da queima da vegetação, com uma redução da fixação do P pelo solo.

Observa-se, por meio das médias gerais, que houve diferença significativa para a concentração do nitrogênio nas áreas com SAFs (Figura 3c) e que os maiores teores foram encontrados no sistema com queima $\left(0,81 \mathrm{~g} \mathrm{~kg}^{-1}\right)$, sendo estes menores do que os quantificados no início do estudo $\left(0,86 \mathrm{~g} \mathrm{~kg}^{-1}\right)$ (Tabela 3). As possíveis perdas de nitrogênio por volatilização podem ser compensadas pelos ganhos estimulados por um aumento na atividade bacteriana do solo logo após um período de queima, que eleva a concentração de $\mathrm{N}$ amonical (Debano et al., 1979). Entretanto, ocorre uma diminuição nos meses subsequentes, principalmente em função do processo de lixiviação; inclusive, não se retorna às concentrações iniciais (Rheinheimer et al., 2003b).

$\mathrm{O}$ maior valor de $\mathrm{N}$ obtido no sistema 1 provavelmente esteja associado à ação da biota, favorecida pelas condições pós-queima, levando ao aumento do teor de $\mathrm{N}$ do solo e justificando os resultados obtidos em relação ao sistema 2. Neste, procedeu-se o manejo do solo com adubação verde de cobertura (Chamaecrista rupens), deixando uma biomassa vegetal mais exuberante. O potássio trocável $\left(\mathrm{K}^{+}\right)$apresentou diferenças significativas entre as áreas com queima e sem queima, sendo que a maior concentração foi encontrada na área de SAF onde ocorre a derrubada e a queima da vegetação (Figura 3a). No entanto, os valores encontrados nos sistemas florestais estudados são baixos (Malavolta, 2006), provavelmente associados a uma baixa quantidade e à diversificação de resíduos vegetais nos sistemas 1 e 2, associados a processos de lixiviação, que se estenderiam ao sistema 3 . O aumento de

Tabela 2. Correlação entre os nutrientes do solo no tratamento com queima da vegetação (S1).

Table 2. Correlation between soil nutrients in dealing with burning of vegetation (S1).

\begin{tabular}{ccccccc} 
& $\mathbf{p H ~} \mathbf{H}_{2} \mathbf{O}$ & $\mathbf{N}$ & $\mathbf{H}^{+}+\mathbf{A l}^{3+}$ & $\mathbf{P}$ & $\mathbf{K}^{+}$ & $\mathbf{C}$ \\
\hline $\mathrm{pH} \mathrm{H} \mathrm{H}_{2} \mathrm{O}$ & 1 & & & & \\
$\mathrm{~N}$ & $0,3767^{\mathrm{ns}}$ & 1 & & & \\
$\mathrm{H}^{+}+\mathrm{Al}_{3}^{+}$ & $-0,7528^{*}$ & $0,0473^{\text {ns }}$ & 1 & & \\
$\mathrm{P}$ & $0,9932^{* *}$ & $0,2708^{\text {ns }}$ & $-0,8056^{* *}$ & 1 & \\
$\mathrm{~K}+$ & $0,4828^{\mathrm{ns}}$ & $0,5967^{\text {ns }}$ & $0,7996^{*}$ & $-0,581^{\mathrm{ns}}$ & 1 & 1 \\
$\mathrm{C}$ & $-0,477^{\mathrm{ns}}$ & $0,6005^{*}$ & $0,7988^{*}$ & $-0,576^{\mathrm{ns}}$ & $0,9999^{* *}$ & 1 \\
\hline
\end{tabular}

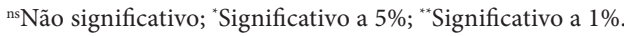


(a)

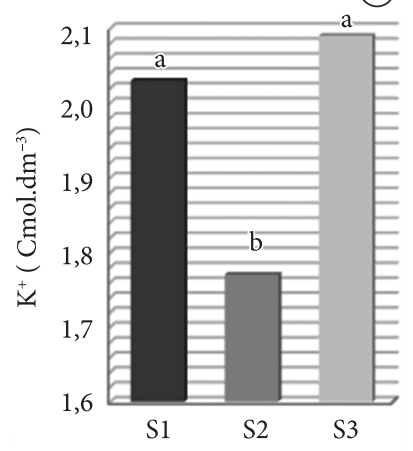

(b)

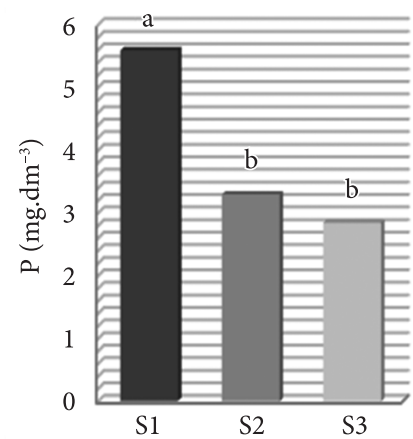

(c)

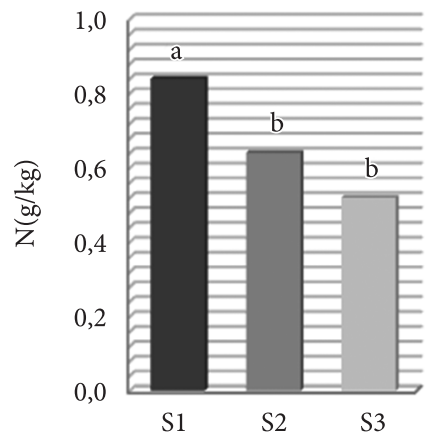

Figura 3. a) Potássio trocável; b) Fósforo; c) Nitrogênio. Letras iguais não diferem entre si pelo teste de Turkey a $5 \%$ de probabilidade.

Figure 3. a) Potassium exchangeable b) Phosphorus c) Nitrogen. Same letter do not differ by testing the Tukey $5 \%$ probability.

$\mathrm{K}^{+}$em solos submetidos à queima é comprovado em diversos estudos; Sanchez \& Vilachica (1983) verificaram incrementos de $56 \%$ nos teores de K após a queima da floresta em razão dos altos teores de $\mathrm{K}$ contidos nas cinzas, que são liberados para a solução do solo.

\subsection{Interações entre os nutrientes nos sistemas}

NA área de capoeira e na área com queima, houve correlação significativa e positiva do carbono com acidez potencial e do nitrogênio com o carbono, além de correlação significativa e negativa da acidez potencial com o fósforo. Note-se que, no sistema em que houve raleamento da vegetação, não ocorreu correlação do carbono com nitrogênio nem com acidez potencial.

As correlações significativas e positivas entre carbono orgânico e acidez potencial (Tabela 4) são características dos solos altamente intemperizados da Amazônia, nos quais a matéria orgânica é a principal fonte de acidez (Ruivo et al., 2007). Tal fato ocorre porque a matéria orgânica em solos ácidos desempenha um importante papel na disponibilidade de nutrientes, pois a maior parte da capacidade de troca catiônica (CTC) desses solos é decorrente dos coloides orgânicos. Para Sanchez (1981), a correlação positiva do carbono com o nitrogênio é comum, haja vista que quase a totalidade do nitrogênio do solo provém da mineralização da matéria orgânica.

Nos ecossistemas amazônicos, o aumento da acidez do solo implica na redução da disponibilidade de fósforo (Heldin et al., 2003). Foi verificada correlação positiva entre $\mathrm{pH}$ e fósforo no sistema manejado com queima, enquanto no SAF sem queima a correlação foi negativa. Com a queimada da vegetação, ocorreu um leve aumento do $\mathrm{pH}$ no sistema 1 e, consequentemente, redução da fixação do $\mathrm{P}$, especialmente afetado pela variação do $\mathrm{pH}$ Malavolta (1976). Para o autor, esse elemento tem a sua maior solubilidade associada a um $\mathrm{pH}$ em torno de 5,5-6,0 e, à medida que o $\mathrm{pH}$ atinge valores menores que 5,0, a disponibilidade do fósforo diminui por causa da formação de fosfatos de ferro e alumínio.

Nas três áreas, verificou-se baixa correlação entre pH e N. Segundo Sanchez (1981) e Brady (1989), tal padrão pode ser explicado pela alta solubilidade de sais nitrogenados inorgânicos em toda a faixa de $\mathrm{pH}$. $\mathrm{O}$ pH do solo nos sistemas estudados, assim como o observado na maioria dos trabalhos realizados em solos amazônicos, apresentou-se inferior a 6,0, sendo que a mineralização de $\mathrm{N}$ é maior entre $\mathrm{pH}$ 6,0 e 8,0.

Apenas na área onde houve raleamento da vegetação, foi verificada a correlação significativa entre $\mathrm{pH}$ e carbono, o que pode ser explicado pelo teor de matéria orgânica presente no solo. Para Martins \& Cerri (1986), esse fator está relacionado à mineralização da matéria orgânica, que recompõe o solo de bases trocáveis. $\mathrm{O}$ pH influencia a atividade microbiana do solo, que aumenta à medida que o pH também aumenta, até atingir valores que favoreçam a liberação de $\mathrm{OH}^{-}$e cátions básicos, que 
Tabela 3. Correlação entre os nutrientes do solo no tratamento com raleamento da vegetação (S2).

Table 3. Correlation between soil nutrients in the vegetation thinning treatment (S2).

\begin{tabular}{ccccccc} 
& $\mathbf{p H ~} \mathbf{H}_{\mathbf{2}} \mathbf{O}$ & $\mathbf{N}$ & $\mathbf{H}^{+}+\mathbf{A l}_{3}{ }^{+}$ & $\mathbf{P}$ & $\mathbf{K}^{+}$ & $\mathbf{C}$ \\
$\mathrm{pH} \mathrm{H} \mathrm{H}_{2} \mathrm{O}$ & 1 & & & & \\
$\mathrm{~N}$ & $-0,0869^{\text {ns }}$ & 1 & & & \\
$\mathrm{H}^{+}+\mathrm{Al}^{3+}$ & $-0,1857^{\text {ns }}$ & $-0,926^{* *}$ & 1 & & \\
$\mathrm{P}$ & $-0,8847^{* *}$ & $-0,26^{\text {ns }}$ & $0,5701^{\text {ns }}$ & 1 & 1 \\
$\mathrm{~K}^{+}$ & $0,9416^{* *}$ & $-0,3199^{\text {ns }}$ & $0,1149^{\text {ns }}$ & $-0,6763^{*}$ & & 1 \\
$\mathrm{C}$ & $0,9411^{* *}$ & $-0,3216^{\text {ns }}$ & $0,1174^{\text {ns }}$ & $-0,6753^{*}$ & $0,9999^{* *}$ & 1 \\
\hline
\end{tabular}

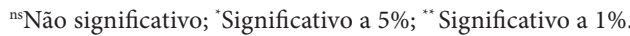

Tabela 4. Correlação entre os nutrientes do solo na área sob capoeira (S3).

Table 4. Correlation between soil nutrients in poultry in the area (S3).

\begin{tabular}{ccccccc} 
& $\mathbf{p H ~} \mathbf{H}_{2} \mathbf{O}$ & $\mathbf{N}$ & $\mathbf{H}^{+}+\mathbf{A l}_{3}{ }^{+}$ & $\mathbf{P}$ & $\mathbf{K}^{+}$ & $\mathbf{C}$ \\
\hline $\mathrm{pH} \mathrm{H} \mathrm{H}_{2} \mathrm{O}$ & 1 & & & & \\
$\mathrm{~N}$ & $-0,4597^{\text {ns }}$ & 1 & & & & \\
$\mathrm{H}^{+}+\mathrm{Al}^{3+}$ & $-0,7053^{*}$ & $0,899^{* *}$ & 1 & & \\
$\mathrm{P}$ & $0,3519^{\text {ns }}$ & $-0,8525^{* *}$ & $-0,894^{* *}$ & 1 & 1 & 1 \\
\hline $\mathrm{K}^{+}$ & $-0,1826^{\text {ns }}$ & $0,8933^{* *}$ & $0,6122^{*}$ & $-0,533^{\text {ns }}$ & 1 & \\
$\mathrm{C}$ & $-0,1881^{\text {ns }}$ & $0,8949^{* *}$ & $0,6154^{*}$ & $-0,5341^{\text {ns }}$ & $0,9999^{* *}$ & 1 \\
\hline
\end{tabular}

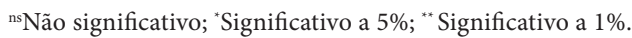

irão neutralizar os íons $\mathrm{H}^{+}$pela decomposição e pela mineralização da matéria orgânica (Silva et al., 2006).

\section{CONCLUSÃO}

Os maiores valores para $\mathrm{pH}$, fósforo $\mathrm{e}$ acidez potencial são observados na área sob desflorestamento e queima da vegetação, indicando que o efeito fertilizador das cinzas resultantes da queima ainda atua sobre o solo.

Os menores valores de C, N, P e pH são evidenciados na área do SAF manejado sem queima, indicando que a Chamaecrista rupens não se mostra eficaz, pelo menos a princípio, no sistema avaliado.

Nas áreas de capoeira, evidenciam-se os maiores teores de carbono orgânico e potássio trocável, indicando maior estabilidade da vegetação e da ciclagem de nutrientes.

\section{STATUS DA SUBMISSÃO}

Recebido: 22/08/2011

Aceito: $24 / 03 / 2012$

Publicado: 30/09/2012

\section{AUTOR(ES) PARA CORRESPONDÊNCIA}

\section{Rosecélia Moreira da Silva Castro}

Museu Paraense Emílio Goeldi,

Coordenação Ciências da Terra e Ecologia,

Av. Perimetral, 1901, Terra Firme,

CEP 66077-530, Belem, PA, Brasil

e-mail: celitamoreira@hotmail.com

\section{REFERENNCIAS}

Brady NC. Natureza e propriedades dos solos. 7th ed. Rio de Janeiro: Freitas Bastos; 1989.

Castro RM, Ruivo ML P, Silva MFF, Picinin JL, Rodrigues E. Conteúdo de nutrientes na serapilheira e a influência da sazonalidade em um sistema agroflorestal com queima e sem queima no nordeste paraense, Bragança-Pará. Enciclopédia Biosfera 2010; 6(11): 1-15.

Debano L, Eberlein G, Dunn P. Effects of burning on Chaparral soils: I Soil nitrogen. Soil Science Society of American Journal 1979; 43(3):504-509. http://dx.doi. org/10.2136/sssaj1979.03615995004300030015x

Denich M. Estudos da importância de uma vegetação secundária nova para o incrementoda produtividade do sistema de produção na Amazônia Oriental Brasileira [tese]. Belém: Empresa Brasileira de Pesquisa Agropecurária; 1991. 
Embrapa. Centro nacional de pesquisa de solos. Sistema brasileiro de classificação de solos. Brasília: Embrapa; 1999.

Embrapa. Manual de métodos de análise de solo. Centro Nacional de Pesquisa de Solos. 3rd ed. Rio de Janeiro: Embrapa; 1997.

Ferreira MSG. Bacurizeiro (Platonia insignis Mart.) em florestas secundárias: possibilidades para o desenvolvimento sustentável no Nordeste Paraense [dissertação]. Brasília: Universidade de Brasília; 2008.

Gomes DMA. Cadeia de Comercialização de Produtos de Floresta Secundária dos Municípios de Bragança, Capitão Poço e Garrafão do Norte - Pará [dissertação]. Belém: Universidade Federal do Pará; 2007.

Gliessman S. Agroecologia: processos ecológicos em agricultura sustentável. 2nd ed. Porto Alegre: Editora UFRGS; 2001.

Heldin LO, Vitousek PM, Matson PA. Nutrient losses over for million years of tropical forest development. Ecology 2003; 84(9):2231-2255. http://dx.doi. org/10.1890/02-4066

Heringer I, Jacques AVÁ, Bissani CA, Tedesco M. Características de um latossolo vermelho sob pastagem natural sujeita a ação prolongada do fogo e de práticas alternativas de manejo. Ciência Rural 2002; 32(2):309-314.

Hölscher D, Ludwig B, Moller MRF, Folster HH. Dynamic of soil chemical parameters in shifting agriculture in the Eastern Amazon. Agriculture, Ecosystems \& Environment 1997; 66:153-163. http://dx.doi.org/10.1016/S0167-8809(97)00077-7

Instituto Brasileiro de Geografia e Estatística - IBGE. Censo 2010. Rio de janeiro: IBGE; 2010.

Lemos RC, Santos RD. Manual de descrição e coleta de solo no campo. Campinas: Sociedade Brasileira de Ciência do Solo; Serviço Nacional de Levantamento e Conservação de Solos; 2002. 36 p.

Lima SS, Leite LFC, Oliveira FC, Costa DB. Atributos químicos e estoques de carbono e nitrogênio em argissolo vermelho-amarelo sob sistemas agroflorestais e agricultura de corte e queima no norte do Piauí. Revista Àrvore 2011; 35(1): 51-60. http://dx.doi.org/10.1590/ S0100-67622011000100006

Lima SS, Leite LFC, Oliveira FC, Castro AAJF, Costa DB, Gualter RMR. Teores de nutrientes da serapilheira e do solo sob sistema agroflorestal em área de transição no norte do Piauí. Revista Brasileira de Agroecologia 2007; 2(2).

Malavolta E. Manual de nutrição mineral de plantas. Ceres; 2006.

Malavolta E. Manual de química agrícola: nutrição de plantas e fertilidade do solo. 3rd ed. Ceres; 1976.
Martins PFS, Cerri CC. Implicações ecológicas e agronômicas da exploração da Amazônia, relacionadas com as modificações da matéria orgânica. In: Anais do Simpósio do Trópico Úmido; 1986; Belém. Belém: EMBRAPA/CPATU; 1986. p. 71-81 .

Melo MS. Florística, fitossociologia e dinâmica de duas florestas secundárias antigas com histórias de uso diferentes no nordeste do Pará-Brasil [dissertação]. Piracicaba: Escola Superior de Agricultura "Luiz de Queiroz", Universidade de São Paulo; 2004.

Neary GD, Klopatek CC, Debano LF, Ffolliott PF. Fire effects on belowground sustainability: a review and synthesis. Forest Ecology and Management 1999; 122(1-2): 51-71. http://dx.doi. org/10.1016/S0378-1127(99)00032-8

Novais FR, Alvarez VH, Barros NF, Fontes RL, Cantarutti RB, Neves JC. Fertilidade do solo. Viçosa: Sociedade Brasileira da Ciência do Solo; 2007.

Nepstad DC, Moreira AG, Alencar AA. Flames in the rain forest: origins, impacts and alternatives to amazonian fire: The pilot program to conserve the brazilian rain forest. Brasília: Banco Mundial; 1999. 161 p.

Osakada A. Desenvolvimento inicial de sangue-dedragão (croton lechleri müll. arg.) sob diferentes classes de solos, corretivos e níveis de luminosidade na Amazônia central [dissertação]. Manaus: Instituto Nacional de Pesquisas da Amazônia; 2009.

Ribeiro MS. Manejo de sistemas agroflorestais com Paricá (Schizolobium amazonicum Huber) e Caupi(Vigna unguiculata (l.) Walp.) em área de vegetação secundária, em Bragança-PA [tese]. Belém: Universidade Rural da Amazônia; 2009.

Rheinheimer DS, Santos JCP, Fernandes VBB. Modificações nos atributos químicos de solo sob campo nativo submetido à queima. Ciência Rural 2003a; 33(1): 75-81.

Rheinheimer DS, Santos JCP, Fernandes VBB, Mafra AL, Almeida JA. Modificações nos atributos químicos de solo sob campo nativo submetido à queima. Ciência Rural 2003b; 33(1): 49-55. http://dx.doi.org/10.1590/ S0103-84782003000100008

Rios M, Martins da Silva RCV, Sabogal C, Martins J, Silva RN, Brito RR et al. Benefícios das plantas da capoeira para a comunidade de Benjamin Constant, Pará, Amazônia Brasileira. CIFOR; 2001. 54p .

Ruivo MLP, Barreiros JAP, Silva RM, Sá LDA; Lopes ELN. LBA-ESECAFLOR Artificially Induced Drought in Caxiuanã Reserve,Eastern Amazonia: Soil Properties and Litter Spider Fauna. Earth Interactions 2007; 11(8):1-13. http://dx.doi.org/10.1175/ EI168.1

Sanchez PA. Suelos del Trópico: características y manejo. San José: IICA; 1981. 660 p. 
Sanchez PA, Vilachic AJH. Soil fertility dynamics after clearing a tropical rainforest in Peru. Soil Science Society of America Journal 1983; 47: 1171-1178. http://dx.doi. org/10.2136/sssaj1983.03615995004700060023x

Santos D, Bahia VG, Teixeira WG. Queimadas e erosão do solo. Informe Agropecuário 1992; 16(176): 62-68.

Silva GR, Silva JRML, Melo VS. Efeitos de diferentes usos da terra sobre as características químicas de um latossolo amarelo do Estado do Pará. Acta
Amazônia 2006; 36(2): 151-158. http://dx.doi. org/10.1590/S0044-59672006000200004

Souza EC. 500 Perguntas e respostas sobre adubos e adubação. Funesp; 1995.99 p.

Vieira ICG, Toledo PM, Almeida A. Análise das modificações da paisagem da região bragantina, no Pará, integrando diferentes escalas de tempo. Ciência e Cultura 2007; 59(3): 27-30.

Vieira LS, Santos PCTC. Amazônia: seus solos e outros recursos naturais. Agronômica Ceres; 1987. 416 p. 